\title{
Pandemia de COVID19: implicações para (in)segurança alimentar e nutricional
}

A presente edição da Revista Ciência \& Saúde Coletiva apresenta 18 artigos na temática de Segurança Alimentar e Nutricional. Um conjunto diverso que inclui um ensaio sobre os nexos entre alimentação e saúde e estudos originais sobre o diagnóstico da insegurança alimentar e nutricional, com uso de diversas abordagens metodológicas, contextos e sujeitos.

O Brasil faz parte de um grupo de países, um pouco mais de uma centena, que reconhece, seja por meio de marcos legais e normativos nacionais ou pela assinatura de tratados internacionais, o direito à alimentação como um direito humano. Esse compromisso é efetivado pelo desenvolvimento de políticas públicas para promover, proteger e prover meios pelos quais todas as pessoas possam se alimentar com dignidade.

O debate sobre saúde, nutrição e segurança alimentar não poderia ser apresentado em momento mais oportuno. Este número é lançado no meio da pandemia de COVID-19 que leva ao aumento da insegurança alimentar e nutricional de indivíduos, famílias e comunidades.

Os impactos da COVID19 sobre a segurança alimentar e nutricional serão heterogêneos, pois resultam de elementos relacionados aos fatores de risco até agora identificados para o pior prognóstico clínico da infecção pelo coronavírus, tais como obesidade e outras doenças crônicas, e as diferentes formas de má nutrição que se agravam no contexto de emergência sanitária.

A renda familiar está associada à segurança alimentar e nutricional. É sólida a evidência de que políticas sociais e econômicas voltadas ao aumento da renda das famílias brasileiras resultaram em redução da fome e da desnutrição infantil ${ }^{1,2}$. Segundo o IBGE, em 2018, 25,3\% da população brasileira vivia em situação de pobreza ou extrema pobreza. São famílias cuja experiência da insegurança alimentar não será uma novidade. Contudo, suas vulnerabilidades são ampliadas com a COVID19. A necessária medida de isolamento social, quando somada à instabilidade no trabalho e renda das famílias pode ocasionar redução no acesso a alimentos e, consequentemente, piora na qualidade da alimentação e até mesmo fome. Por isso, medidas voltadas à garantia de renda emergencial estão entre as primeiras defendidas para a proteção social e a promoção da segurança alimentar e nutricional.

A resposta do poder público não ocorre com a urgência que o momento exige. Paralelamente, observamse iniciativas de provimento emergencial de alimentos e refeições nas comunidades pobres e periféricas de centros urbanos, fruto da solidariedade entre os iguais. Vale o destaque para o papel indutor que a sociedade civil e as organizações de controle social têm exercido nas políticas de segurança alimentar e nutricional no Brasil. Uma voz que, novamente, se apresenta de forma propositiva na defesa do fortalecimento de programas estratégicos, como o Programa Nacional de Alimentação Escolar (PNAE), Programa de Aquisição de Alimentos (PAA) e de Equipamentos Públicos como bancos de alimentos e restaurantes populares, com vista à garantia do Direito Humano à Alimentação Adequada em tempos de COVID19.

Quanto aos consumidores em geral, a pandemia agregou um novo contingente populacional que, agora, experimenta a sensação de insegurança alimentar, seja por receio de falta de alimentos ou pela preocupação com a segurança sanitária dos mesmos. São importantes as ações que garantam o abastecimento, ponto central do sistema alimentar, e de educação em saúde voltada às boas práticas de higiene, tanto no âmbito doméstico como no varejo de alimentos.

Globalmente, ganha força o debate sobre a necessidade de um sistema alimentar que promova saúde e justiça social, garanta maior resiliência ecológica ao planeta e esteja alinhado aos objetivos do desenvolvimento sustentável ${ }^{3}$. Uma agenda necessária que não deve ser esquecida no pós-pandemia.

Patricia Constante Jaime (https://orcid.org/0000-0003-2291-8536) ${ }^{1}$

${ }^{1}$ Faculdade de Saúde Pública, Universidade de São Paulo. São Paulo SP Brasil.

\section{Referências}

1. Organização das Nações Unidas para a Alimentação e a Agricultura (FAO). SOFI: o estado da segurança alimentar e nutricional no Brasil 2015. FAO Brasil, out 2015. [acessado 2020 Maio 08]. Disponível em: http://www.fao.org/fileadmin/user_upload/ FAO-countries/Brasil/docs/SOFI_Brasil_2015_final.pdf

2. Monteiro CA, Benicio MHD, Konno SC, Silva ACF, Lima ALL, Conde WL. Causas do declínio da desnutrição infantil no Brasil, 1996-2007. Rev Saude Publica 2009; 43(1): 35-43.

3. Swinburn BA, Kraak VI, Allender S et al. The Global Syndemic of Obesity, Undernutrition, and Climate Change: The Lancet Commission report. Lancet 2019; 393(10173):791-846. 